\title{
Effects of neuropeptide $Y$, insulin, 2-deoxyglucose, and food deprivation on food-motivated behavior
}

Received: 12 August 1994/ Final version: 1 March 1995

\begin{abstract}
The current study demonstrates the ability of neuropeptide $Y(N P Y)$ to increase break points under a progressive ratio 1 (PR1) reinforcement schedule. An initial response resulted in delivery of a food reinforcer (45 mg pellet) under the PR1, and an additional response was required for each successive reinforcer. The break point, the number of responses emitted to obtain the last reinforcer, is considered a measure of reinforcing efficacy or motivational strength of the food reinforcer. NPY $(0.3-10 \mu \mathrm{g})$ significantly increased break point to levels comparable to those produced by $36-48 \mathrm{~h}$ of food deprivation. Although insulin (3-8 U/ kg) and 2-deoxyglucose $(150-250 \mathrm{mg} / \mathrm{kg}$ ) also increased food intake, neither increased break points to levels produced by NPY or food deprivation. These data suggest that NPY may change the value of food in ways that cannot be accounted for by changes in insulin, glucose levels or intracellular glucoprivation. These results emphasize that simply measuring the amount of freely available food eaten is not a fully adequate measure of the strength of the feeding behavior.
\end{abstract}

Key words Neuropeptide $Y \cdot$ Insulin ·

2-Deoxyglucose $\cdot$ Food deprivation $\cdot$ Motivation

Reinforcer efficacy $\cdot$ Rats

\section{Introduction}

Neuropeptide Y, first identified by Tatemoto, Carlquist and Mutt (1982), is one of the most abundant peptides

D. C. Jewett $(\triangle) \cdot$ J. Cleary D. W. Schaal $\cdot$ T. Thompson

Department of Psychology, University of Minnesota,

Minneapolis, MN 55455, USA

I. Cleary - A. S. Levine

Veterans Affairs Medical Center, Minneapolis, MN 55417, USA

Present address:

Department of Pharmacology, University of Michigan, 130 I

MSRB III, Ann A.rbor, MI 48109-0632, USA present in the central nervous system (Allen et al. 1983). It is widely distributed in the brain with particularly high concentrations in the hypothalamus (McDonald 1988). Exogenous administration of NPY altered passive avoidance performance (Flood et al. 1987), sexual behavior (Clark et al. 1985), cardiovascular function (Boublik et al. 1989) and feeding (Clark et al. 1984).

Neuropeptide Y's effects on feeding are reliable and robust. NPY $(2-10 \mu \mathrm{g})$, administered intracerebroventricularly (ICV), increased feeding in rats (Clark et al. 1984), and enhanced nocturnal feeding, deprivationinduced feeding, and feeding during the light period of the light/dark cycle when rats normally do not eat (Levine and Morley 1984). NPY, administered directly into the paraventricular nucleus of the hypothalamus (PVN), increased food and water intake, but not other behaviors (Stanley and Leibowitz 1985).

Few studies have shown increases in food-reinforced responding in non-restricted animals. NPY increased milk-reinforced lever-pressing in non-restricted mice (Flood and Morley 1991). NPY also increased foodreinforced lever pressing in food-satiated rats (Jewett et al. 1992). In that study, NPY's effect was examined under three different food availability conditions, a fixed ratio 40 (FR40) requiring 40 lever-presses for each food pellet, a fixed interval 15-s (FI 15-s) which delivered a food pellet for the first response occurring $15 \mathrm{~s}$ after each reinforcer, and under conditions of freely available food (FF). NPY (5 $\mu \mathrm{g})$ significantly increased food intake and/or lever-pressing under all conditions. Food intake following NPY was inversely related to the amount of effort required to obtain the food, and the strength of the food-induction increased with successive daily injections under the high-effort condition (FR40).

The relatively large amount of work expended for food after NPY under the high-effort condition contrasts with reports of feeding in rats lesioned in the ventromedial hypothalamus (VMH) (Anand and Brobeck 1951). VMH-lesioned rats eat large amounts 
of palatable food when response requirements are minimal (to the point of becoming obese), but drastically decrease intake when substantial effort is required to obtain food (Teitelbaum 1957). Under these conditions, VMH-lesioned rats lever-press and subsequently eat considerably less than non-lesioned rats. The results suggest that measures of food intake alone do not fully indicate the "motivation" to eat induced by VMH lesions.

The current study compares NPY-induced feeding with other methods of increasing food intake, that is, peripheral injections of insulin or 2-deoxyglucose (2DG), and food deprivation to determine to what extent these orexigens increase the reinforcing efficacy of food or the "motivation" to eat. The progressive ratio schedule of food reinforcement (PR) used in the current study requires an increasing number of lever presses for each successive reinforcer. Eventually the performance (number of presses emitted by a subject) falls below a preset criterion required to obtain a reinforcer. The number of responses emitted to obtain the last reinforcer is the break point and is considered a measure of reinforcing efficacy of the food reinforcer (Hodos 1961). Break points under PR schedules have been shown to be sensitive to factors influencing reinforcing efficacy, such as reinforcer magnitude (Hodos and Kalman 1963), self-administered drug dose (Griffiths et al. 1978), or food deprivation level (Hodos 1961).

\section{Materials and methods}

\section{Subjects}

Eleven male Sprague-Dawley rats (Harlan, Madison, Wis.), 90 days old and $250-275 \mathrm{~g}$ at the beginning of the experiment, were housed in individual cages and maintained on a 12-h light/dark cycle with lights on at 0630 and off at 1830 hours. Food pellets in operant chamber and home cage were of identical composition (\#F0021, Biosery Holton Industries, Frenchtown, N.J.). Rat chow was also available in the home cage during some portions of the procedure (Laboratory Rat Chow, Raulston-Purina, St Louis, Mo.). Water was available at all times in the home cage.

\section{Apparatus}

Experimental sessions were conducted in five standard two-lever operant chambers (Coulbourn Instruments, Lehigh Valley, Pa.), equipped with feeders which could deliver $45 \mathrm{mg}$ food pellets. Chambers were enclosed in sound-attenuating cubicles in a room with white noise present continuously. Experimental conditions and data recording were executed by MED-PC software (MED Associates, East Fairfield Vt.) and a Zenith ZW Z286 computer (Zenith Electronics, St Joseph, Mich.), located in an adjacent room. Home cages were individual stainless steel, equipped with water bottles and spouts.

\section{Surgery}

Rats were anesthetized with sodium pentobarbital $(40 \mathrm{mg} / \mathrm{kg}$ IP) and fitted with a 20 gauge guide cannula terminating in the right lateral ventricle. Stereotaxic coordinates, with incisor bar set $3.0 \mathrm{~mm}$ below the interaural line, were $1.5 \mathrm{~mm}$ lateral, $1.0 \mathrm{~mm}$ posterior, and $3.5 \mathrm{~mm}$ below the surface of the skull. Rats were allowed to recover for 7 days before behavioral training began. Cannula placement was verified by injecting dye into the cannula following sacrifice. If microtome brain slices through the section that included the cannula showed dye in the lateral ventricle, the cannula was considered to have been properly placed. All rats in the present study met this criterion.

\section{Drug preparation and administration}

Neuropeptide Y (Peninsula Laboratories, Belmont, Calif) was diluted in $0.9 \%$ saline and stored in sealed plastic containers at $-20^{\circ} \mathrm{C}$. It was thawed to room temperature and slowly (30 s) administered ICV at a constant volume of $5.0 \mu 1$ using a $50-\mu l$ microsyringe. Vehicle injections were $5.0 \mu$ saline. Insulin (Regular Porcine Insulin, Novo Nordisk Pharmaceuticals, Princeton, N.J.) and 2-deoxy-Duglucose (Sigma, St Louis, Mo.) were diluted with $0.9 \%$ saline, stored in sealed plastic containers and refrigerated until 30 min prior to use.

\section{Procedures}

Body weights of five rats were slowly reduced to $80 \%$ of their freefeeding levels and rats were trained to press the right lever to obtain food ( $45 \mathrm{mg}$ pellet) by the method of successive approximations. Initially, one lever-press produced a reinforcer. This response requirement was slowly increased until ten lever-presses were required to produce a food pellet (FR10). After three sessions, the reinforcement schedule was changed from an FR10 to a PR1, under which the initial lever press was reinforced, but the number of responses required to obtain food increased by one lever-press for each successive reinforcer. The session continued until 3 min elapsed with no responding. The number of responses emitted in the last completed ratio was termed the break point.

Responding stabilized after $20-40$ sessions of training under the PR schedule of reinforcement. Stability criteria were ten consecutive sessions with no increasing or decreasing trends according to the Tryon C-test (Tryon 1982) and the last five sessions with break points differing by no more than $\pm 10 \%$ of the mean of the these break points. Rats were cannulated after criteria had been reached. Following surgery and recovery, sessions continued until responding was again stable. Body weights were then returned to free-feeding levels by providing ad lib food and water in the home cage. Under food and water satiation, responding was minimal.

When no lever-pressing trends were observed under the above conditions and responding was minimal, the effects of NPY, food deprivation, insulin, and 2-DG were assessed under the PR schedule of reinforcement. Within a given treatment condition (initially NPY, then food deprivation, the insulin and finally 2-DG), the order of administration for all doses or imposition of number of hours of deprivation were randomly selected for each subject. Drug or deprivation conditions were spaced so as to occur approximately every fourth session. Rats were first injected (ICV) with saline $(5 \mu 1)$ or NPY $(0.3-10 \mu g$ in $5 \mu 1) 30 \mathrm{~min}$ prior to the session. Next, the effects of food deprivation were tested and rats were food deprived for $12-48 \mathrm{~h}$ prior to experimental sessions. Rats received saline injections $30 \mathrm{~min}$ prior to these experimental sessions. Subsequent test sessions were preceeded by SC administration of insulin $(3,6$, and $8 \mathrm{IU} / \mathrm{kg})$. Finally, rats received SC injections of 2-DG $(150,200$, and $250 \mathrm{mg} / \mathrm{kg}$ ). All sessions were conducted $1 \mathrm{~h}$ after the light cycle began and $30 \mathrm{~min}$ after drug or saline administration. Total foodreinforced lever presses, cumulative post-reinforcement pause time (seconds between reinforcer and next lever-press), break point and session time were recorded.

Rats receiving freely available food ( $\mathrm{FF}, n=6$ ) were maintained at their free-feeding weights throughout the study. Rats in this group 
received SC injections of saline $(0.9 \%)$, insulin $(3,6$ and $8 \mathrm{IU} / \mathrm{kg})$ and 2-DG $(150,200$, and $250 \mathrm{mg} / \mathrm{kg})$ in a random order. At least 2 days separated drug administrations. Injections oceurred during the first $2 \mathrm{~h}$ of the light portion of the 12-h light-dark cycle. After injection, all rats were returned to their home cages and given free access to $\mathrm{I}-\mathrm{g}$ food pellets, identical in composition to those used as reinforcers under the $P R$ schedule. Water was available ad lib. The amount of food consumed was recorded for $30 \mathrm{~min}$ by weighing remaining food and spillage.

Statistics

Dependent measures were compared across drug conditions or hours of deprivation using the repeated measures analysis of variance (RMANOVA). Dunnett's $t$-test was used to compare drug or deprivation conditions to control conditions when RMANOVA was significant.

\section{Results}

Break points, the number of responses required to obtain food reinforcers, were significantly increased following NPY administration relative to break points under saline $[F(4,28)=22.7, P<0.0001]$. Figure 1 depicts break points under the training conditions (20\% deprivation), and following saline, and NPY $(0.3-10 \mu \mathrm{g})$ in the same rats when not food-restricted. Mean break point during the chronic food deprivation condition was significantly higher than break points obtained in non food-restricted animals. Saline administration had no effect on break point. NPY administration significantly increased break points at each dose compared to break points following saline (Dunnett's $t, P<0.05)$. The largest NPY dose $(10 \mu \mathrm{g})$ produced the largest mean break point (54).

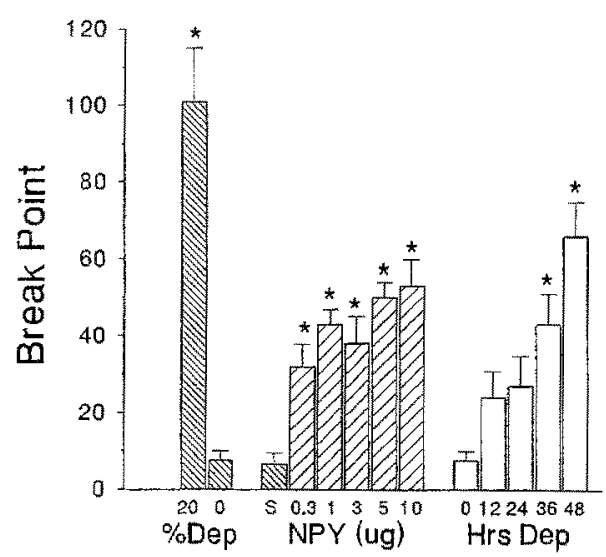

Fig. 1 Effects of NPY and acute food deprivation on break point in rats responding under a PR1 schedule of food presentation. Mean break points $(n=5)$ obtained in rats food restricted to $80 \%$ of their free-feeding weight under training conditions $(20 \% \mathrm{Dep})$, in nonrestricted rats following free access to food $(0 \%$ Dep $)$, and in nonrestricted rats administered saline $(S)$, and $0.3,1,3,5$ and $10 \mu \mathrm{g}$ NPY ICV. Mean break points were also obtained following 0, 12, 24, 36 and $48 \mathrm{~h}$ food deprivation. Asterisks indicate break point significantly different than break point following saline (Dunnett's $i$-test, $P<0.05$ ). The single bracket represents +1 SEM
Table 1 Effect of insulin and 2-deoxyglucose on break point. Data are expressed as the mean break point $(n=5) \pm 1$ SEM

\begin{tabular}{lrr}
\hline Drug condition & Break point & \\
\hline Saline & & $6.8 \pm 2.6$ \\
Insulin & $3 \mathrm{IU} / \mathrm{kg}$ & $11.6 \pm 4.9$ \\
& $6 \mathrm{IU} / \mathrm{kg}$ & $10.0 \pm 4.6$ \\
& $8 \mathrm{IU} / \mathrm{kg}$ & $18.0 \pm 6.3$ \\
$2-\mathrm{DG}$ & $150 \mathrm{mg} / \mathrm{kg}$ & $6.6 \pm 1.5$ \\
& $200 \mathrm{mg} / \mathrm{kg}$ & $9.6 \pm 5.5$ \\
& $250 \mathrm{mg} / \mathrm{kg}$ & $0.8 \pm 0.6$ \\
\hline
\end{tabular}

*Break point significantly different than break point following saline (Dunnett's $t$-test, $P<0.05$ )

Figure 1 also depicts break point following acute food deprivation. Food deprivation significantly increased break point as a monotonic function of hours since availability $[F(4,20)=13.09, P<0.0001]$. Break point following 12 - and $24-\mathrm{h}$ food deprivation was increased to comparable levels. Mean break point following $36-$ and $48-\mathrm{h}$ deprivation was significantly increased compared to break points following no food deprivation $(P<0.05$; Dunnett's $t)$.

Table 1 shows that break points following insulin $(3-8 \mathrm{U} / \mathrm{kg})$ and $2-\mathrm{DG}(150-250 \mathrm{mg} / \mathrm{kg})$ were not significantly different from those following saline $[F(4,24)=1.76, P>0.05]$. Table 1 shows very little responding occurred following $250 \mathrm{mg} / \mathrm{kg} 2-\mathrm{DG}$, but at all other doses of either 2-DG or insulin, mean break point was similar to break point following saline. Insulin and 2-DG significantly increased food intake under conditions of freely available food $F(5,30)=5.21$, $P<0.001]$. Figure 2 depicts amount of food consumed $30 \mathrm{~min}$ after saline, insulin or 2-DG administration. Mean food intake following all doses of insulin (3-8 U/ kg) and 2-DG (150-250 $\mathrm{mg} / \mathrm{kg})$ was significantly increased over food intake following saline administration $(P<0.05$; Dunnett's $t)$.

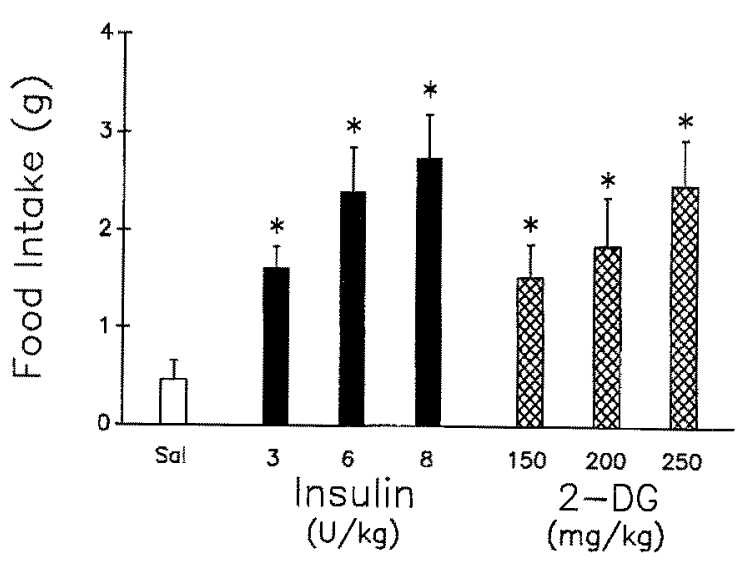

Fig. 2 Effects of insulin and 2-deoxyglucose on food intake. Mean food intake $(n=6)$ was measured for 30 min following an injection of saline $(S a b), 3,6$ and $8 \mathrm{IU} / \mathrm{kg}$ insulin, and 150,200 and 250 $\mathrm{mg} / \mathrm{kg}$ 2-deoxyglucose $(2-D G)$. Asterisks indicate food intake significantly different than food intake following saline (Dunnett's $t$-test, $P<0.05$ ). Brackets represent +1 SEM 


\section{Discussion}

Neuropeptide $Y$ increased break points and amount of food eaten under the PR schedule of reinforcement, These results are consistent with previous studies reporting NPY increased food intake in home cage environments where food was freely available (Clark et al. 1984; Levine and Morley 1984; Stanley and Leibowitz 1985). NPY also increased food-reinforced responding under low effort conditions (Flood and Morley 1991; Jewett et a1. 1992) and even when each food pellet delivery required significant exertion (Jewett et al. 1992). The current study demonstrates NPY's ability to increase break points under a reinforcement schedule thought to be sensitive to factors influencing the reinforcing efficacy of food. As expected, food deprivation also increased break point under the PR schedule. Thirty-six to $48 \mathrm{~h}$ of food deprivation increased PR break point to amounts that are equivalent to those following $5 \mu \mathrm{g}$ NPY injected ICV. This NPY dose is typically employed in free feeding studies and significantly increases grams of food consumed (e.g., Levine and Morley 1984). Chronic food restriction, which lowered body weight to $80 \%$ of free-feeding levels, was substantially more effective in increasing break point than was NPY.

As we have pointed out previously, simply measuring the amount of freely available food eaten is not a fully adequate measure of an agent's ability to affect the reinforcing efficacy of food or the strength of the feeding behavior (Jewett et al. 1992). The PR reinforcement schedule allows comparison of potential shared behavioral mechanisms of action of NPY and other feeding-inducing procedures. In the current study, NPY administration increased break points more than insulin or 2-DG administration. Insulin and 2-DG both significantly increased food intake in non-foodrestricted rats given free access to food. Under similar experimental conditions in non-food-restricted rats (e.g. Jewett et al. 1992), NPY $(5 \mu \mathrm{g})$ produced a $2.4( \pm 0.8) \mathrm{mg}$ increase food intake $30 \mathrm{~min}$ after the injection. Taken together, these data indicate that NPY, insulin, and 2-DG all increased food intake when food was freely available, but only NPY reliably increased food-reinforced responding under the PR schedule. This result suggests the conditions that initiate and maintain feeding induced by NPY are substantially different from those that initiate and maintain feeding following insulin or 2-DG. Administration of insulin or the glucose analog 2-DG both produce glucoprivation, with subsequent increases in food intake (Ritter 1986). However, glucoprivation produced by the two agents is dissimilar. Insulin promotes glucose uptake from the blood into adipose and muscle cells. Exogenous insulin thus reduces circulating glucose levels resulting in hypoglycemia. 2-DG is a glucose analog that cannot be metabolized, blocking glycolysis in all cells of the body including those of the brain (Miselis and Epstein 1975). The net result is intracellular glucoprivation and subsequent hyperglycemia from a sympathoadrenal response. Some investigators have shown that central NPY administration stimulates insulin release (Moltz and McDonald 1985; Abe et al. 1989), while other have not detected NPY-induced changes in insulin levels (Billington et al. 1991). However, neither insulin-induced hyperglycemia nor 2-DG-produced hypoglycemia produced changes in break point comparable to those produced by NPY. NPY changes the value of the food reinforcer in ways that cannot be accounted for by changes in insulin, glucose levels or intracellular glucoprivation.

The ability of food to act as a reinforcer and the strength of the feeding response elicited by an agent involves several components which may not be measurable by the same procedure. Break point in a progressive ratio schedule may be useful in evaluating what has traditionally been called "food drive" or "hunger". Insulin increased break point somewhat, but the effects were small, while NPY produced a significant increase in break point.

Acknowledgements This experiment was in partial fulfillment of the requirements of the $\mathrm{PhD}$ degree for D.C. Jewett. This research was supported by NIDA grant DA02717, awarded to T. Thompson and J. Cleary and NIDA grant DA03999, awarded to A.S. Levine, and by Department of Veterans Affairs Merit Review awarded to J. Cleary. D.C. Jewett was supported under NIDA Training Grant DA07097. The authors wish to thank Martha Grace for her expert technical assistance throughout the project.

\section{References}

Abe M, Saito M, Shimazu T (1989) Neuropeptide Y and norepinephrine injected into the paraventricular nucleus of the hypothalamus activate endocrine pancreas. Biomed Res $10: 431-436$

Allen YS, Adrain TE, Allen JM, Tatemoto K, Crow TJ, Bloom SR, Polak JM (1983) Neuropeptide $Y$ distribution in rat brain. Science 221:877-879

Anand BK, Brobeck JR (1951) Hypothalamic control of food intake in rats and cats. Yale J Biol Med 24:123-14

Billington CJ, Briggs J, Grace M, Levine AS (1991) Effects of intracerebroventricular injection of neuropeptide $\mathrm{Y}$ on energy metabolism. Am J Physiol 260:R321-R327

Boublik J, Scott NA, Brown MR, Rivier JE (1989) Synthesis and hypertensive activity of neuropeptide-Y fragments and analogs with modified N-termini or C-termini or D-substitutions. J Med Chem 32:597-601

Clark JT, Kalra PS, Crowley, WR, Kalra SP (1984) Neuropeptide $\mathrm{Y}$ and human pancreatic polypeptide stimulate feeding behavior in rats. Endocrinology 115:427-429

Clark JT, Kalra PS, Kalra SP (1985) Neuropeptide Y stimulates feeding but inhibits sexual behavior in male rats. Endocrinology $117: 2435-2442$

Flood JF, Morley IE (1991) Increased food intake by neuropeptide $\mathrm{Y}$ is due to an increased motivation to eat. Peptides 12 : $1329-1332$

Flood JF, Hernandez EN, Morley JE (1987) Modulation of memory processing by neuropeptide Y. Brain Res 421:280-290

Griffiths RR, Bradford LD, Brady JV (1979) Progressive ratio and fixed ratio schedules of cocaine-maintained responding in baboons. Psychopharmacology 65:125-136 
Hodos W (1961) Progressive ratio as a measure of reward strength. Science 134:943-944

Hodos W, Kalman G (1963) Effects of increment size and reinforcer volume on progressive ratio performance. J Exp Anal Behav 6: 387-392

Jewett DC, Cleary J, Levine AS, Schaal DW, Thompson T (1992) Effects of neuropeptide $\mathrm{Y}$ on food-reinforced behavior in satiated rats. Pharmacol Biochem Behav 42:207-212

Levine AS, Morley JE (1984) Neuropeptide Y: a potent inducer of consummatory behavior in rats. Peptides 5:1025-1029

McDonald JK (1988) NPY and related substances. Crit Rev Neurobiol 4:97-135

Miselis RR, Epstein AN (1975) Feeding induced by intracerebroventricular 2-deoxy-D-glucose in the rat. Am I Physiol 229: $1438-1447$

Moltz JH, McDonald JK (1985) Neuropeptide Y: direct and indirect action on insulin secretion in the rat. Peptides 6:1155-1159
Ritter S (1986) Glucoprication and the glucoprivic control of food intake. In: Ritter RC, Ritter S, Barnes CD (eds) Feeding behavior: neural and humoral controls. Academic Press, Orlando, pp $271-313$

Stanley BG, Leibowitz SF (1985) Neuropeptide Y injected into the paraventricular hypothalamus: a powerful stimulant of feeding behavior. Proc Natl Acad Sci USA 82: 3940-3943

Tatemoto K, Carlquist M, Mutt V (1982) Neuropeptide Y: a novel brain peptide with structural similarities to peptide $Y Y$ and pancreatic polypeptide. Nature 296: 659-662

Teitelbaum P (1957) Random and food-directed activity in hyperphagic and normal rats. J Comp Physiol Psychol 48:156-163

Tryon WW (1982) A simplified time-series analysis for evaluating treatment interventions. J Appl Behav Anal 15:423-429 